\title{
LeadLets: Towards a Pattern Language for Leadership Development of Human and AI Agents
}

\author{
Triparna de Vreede ${ }^{\mathrm{a}}$, Logan Steele ${ }^{\mathrm{a}}$, GJ de Vreede ${ }^{\mathrm{a}}$, Robert Briggs ${ }^{\mathrm{b}}$ \\ ${ }^{\mathrm{a} U n i v e r s i t y ~ o f ~ S o u t h ~ F l o r i d a, ~}{ }^{\mathrm{b}}$ San Diego State University \\ \{tdevreede,1msteele, gdevreede\}@usf.edu, rbriggs@sdsu.edu
}

\begin{abstract}
Advances in artificial intelligence (AI) technologies have inspired businesses and researchers to identify new ways in which AI can improve our way of life. One such quest lies in giving AIs complex human capabilities - like leadership. We take the first step towards that goal and propose a pattern-based approach to leadership. We argue that leadership best practices are actually a series of mini interventions each of which results in a consistent and desired response from the followers. When codified, these repeatable interventions can serve as foundational blocks for AI algorithms. To this end, we introduce LeadLets: A pattern language that codifies named, scripted, and repeatable leadership techniques that have a predictable influence causing a purposeful effect on one or more individuals. We argue that a pattern-based approach such as LeadLets can create leadership templates that inform programing leadership behavior into AI artifacts and designing leaders development programs.
\end{abstract}

\section{Introduction}

Chris is an innovative leader and the CEO of TLG Technologies which builds robots to help groups in crisis situations. As she reflects on her leadership style, she realizes that she often repeats the same tactics in given type of leadership situation. With further thought, she realizes that she repeats the behaviors as they work every time. If that's the case, she thinks, why not develop a list of techniques that are good solutions for recurring leadership problems, and use this list to train novice leaders at TLG Technologies? 'Indeed,' she thinks, 'Why not collect the best practices of other good leaders?' And then, the epiphany, 'Would it be possible to codify the techniques into their crisis support robots, so that they can be more effective at crisis response?'

Peter Drucker once noted that "the computer makes no decisions; it only carries out orders. It's a total moron, and therein lies its strength...." [29]( p.8). We have come a long way since that era, especially with the upsurge in Artificial Intelligence (AI) systems. We define AI as digital entities that can perform tasks commonly associated with intelligent beings. The role of AI is rapidly advancing from being reactive support providers to being interactive teammates that work hand in hand with teams to facilitate high quality outcomes [47]. We already have AI systems that act as companion robots to provide company to the elderly [45], decision making systems that help us navigate through complex problems [32], and warning systems that protect us in face of danger whether it is on the road [48], severe weather [8], or human deception [26, 27]. However, to our knowledge, research and development has not reached a point where $\mathrm{AI}$ is capable of critical thinking and problem solving at par with human abilities. As a result, superior human capabilities, like leadership, still remains out of reach of AI. The goal of this paper is to take first steps towards bridging this AI leadership gap by recommending a pattern-based approach to codify leadership behaviors.

In this paper we define leadership as a process of influencing one or more co-members of a collective to advance towards one or more shared goals. It is invaluable for an organization to execute its strategy and maintain competitive advantage [37]. So far, it has been a uniquely human capability that is a sought-after by individuals and corporations alike [12]. Considerable effort in research and practice is devoted towards leadership development [38]. However, there appears to be scarce consistent, empirical evidence to support the link between content and conditions of leadership training [19, 23]. In other words, it is difficult to ascribe clear and direct linkages between the leadership concepts taught and leadership behaviors practiced. One way to address this problem is to build a scholarly foundation of evidence-based leadership interventions that are both replicable and transferable. Such evidence-based leadership interventions can also serve as building blocks for AI leadership.

AI leadership can be thought of as the leadership role assumed by the AI artifact to guide a group of followers through a decision-making or problem-solving process. Codified, replicable, and transferrable interventions can lay a firm foundation to create algorithms that can be useful to guide the AI to respond with appropriate leadership behaviors. Thus, it appears that the solution to both advances in leadership AI as well as leadership development will benefit from the successful distillation, codification, and replication of effective leadership behaviors. As a step toward meeting the dual need a) to have a standardized approach to train new leaders and b) to create foundation for AI leadership algorithms, we propose a new approach to leadership based on pattern languages [2]. In this paper we take a first step toward using pattern language principles to identify and codify reusable leadership interventions. 
In the sections that follow, we first discuss the history of leadership behavior research, specifically from the perspective of replicable leadership behaviors. Then we discuss how Collaboration Engineering can provide inspiration to apply a pattern perspective to leadership. Next, we demonstrate how leadership best practices can be identified and codified as patterns and techniques which can be used as AI design blocks as well as leadership development tools. To this end, we rely on interviews with successful leaders and review of leadership literature to identify leadership patterns and techniques as leadership best practices. We present a template to codify the leadership best practices, offer preliminary examples of leadership patterns and present three codified and transferrable leadership techniques that have been distilled from the aforementioned patterns as a "proof of concept". Finally, we discuss the implications of this work and outline directions for future research.

\section{Background}

As noted above, the first step towards developing leadership AI is to code the leadership process into observable behaviors that move one or more followers towards achieving the leader's goal [26]. Importantly, these coded behaviors must be reusable, predictable, and easily transferable for them to be useful as a foundation for both novice humans and AI algorithms [14]. One might intuit that the data needed for this effort would be readily available in the literature, given the more than 60 -year history of studying leadership behaviors [40]; however, the methods used to date do not yet meet the three essential criteria of reusability, predictability, and transferability. Below, we provide a brief review of the history of leader behavior research and explain how and why it falls short of the three essential criteria. We then propose a new way forward borrowing from the discipline of Collaboration Engineering.

\subsection{History of Leader Behavior Research}

The formal study of leadership - influencing one or more individuals towards achieving a shared goal [52]began 150 years ago with a search for heritable traits that could distinguish effective and ineffective leaders [31]. After nearly a century, the trait paradigm gave way to the behavior paradigm of leadership research $[13,34$, 49], which emphasized the things that leaders actually do or actions that they take. Generally, these approaches relied on descriptive methods of data collection (e.g., direct observation, anecdotes, behavior description

\footnotetext{
1 These meta-categories are otherwise referred to ask initiating structure and consideration (Fleishman, 1954), production-centered and employee-centered (Likert, 1961), or concern for production and concern for people (Blake \& Mouton, 1964).
}

questionnaires). Through the use of factor analysis, all of these early studies converged on the discovery of two meta-categories of leadership behavior-task-oriented and relations-oriented [52]. ${ }^{1}$ Task-oriented leadership behaviors are actions that directly support achieving a shared goal, while relations-oriented leadership behaviors are actions that influence others to allocate effort towards achieving a short goal.

Since the 1950s and 1960s, behavioral frameworks have become the dominant approach in leadership research [28]. Expanding from the original two dimensions, other leader behavior frameworks include passive leader behaviors (e.g., laissez-faire; [10]), inspirational leader behaviors (e.g., transformational and charismatic; [9, 18], and, most recently, value-based and moral leader behaviors (e.g., authentic, ethical, and servant; $[15,39,41]$ ).

\subsection{Limitations of Prior Leader Behavior Research}

Despite their popularity in academia, these frameworks prove to be very challenging to translate into practice, especially when it concerns the development of new leaders, human or machine. We believe the primary reason for this is the competing values between science and practice [51]. Specifically, in the study of leadership behaviors, parsimony and generalizability have been prioritized, which necessarily forces a tradeoff with precision and accuracy $[3,4,30]$. For example, it is wellestablished across multiple meta-analyses that relationsoriented behaviors are positively related to a team's performance $[16,33,35]$. A practitioner reading this finding would likely be interested in seeing leaders in his/her organization trained in executing these behaviors. To understand what it means effectively execute relationsoriented behaviors, one could seek insight from the definition, provided above, but it lacks sufficient detail to inform training on its own. A next logical step might be to review measures of relations-oriented behavior seeking more detail. Indeed, some items in the widely used Leader Behavior Description Questionnaire [49] may be useful, such as "I allow the members complete freedom in their work" or "I publicize the activities of the group." However, the vast majority of the 100 items do not describe behaviors that are reusable, transferable, and have a predictable effect. A few examples include, "I am friendly and approachable," "I make pep talks to stimulate the group," and "I do little things to make it pleasant to be a member of the group." $"$ The lack of specificity in describing leader behavior in prior research is a problem widely recognized by scholars (e.g., $[5,17,50])$. To the extent that there are multiple ways to execute a given behavioral description, it

\footnotetext{
2 In the interest of transparency and to avoid impressions that we "cherry-picked" items that support our argument, readers are encouraged to review the items themselves at https://cyfar.org/sites/default/files/LBDQ_1962_Self_Assessment.pdf
} 
automatically fails to meet all of the criteria specified above - reusability, predictability, and transferability. It is not reusable if a behavior is not described in sufficient detail to be replicated. It cannot provide a predictable effect if each time the behavior is executed, it is executed in a different manner. Finally, it is not transferable because the lack of specificity of the practical execution of the leadership behavior makes it impossible to provide clear instructions to novices. One pathway to resolve this conundrum can be found in the field of Collaboration Engineering.

\subsection{Collaboration Engineering}

Leadership behaviors have been extensively studied from a pattern perspective in the context of a special type of leaders: Facilitators. Facilitators support small and large teams in accomplishing joint goals by designing and moderating a collaborative team process. While organizational teams can benefit greatly from facilitation support, professional facilitators are expensive to hire or train. Further, internal facilitators are difficult to retain over time as their skills let them raise through the ranks swiftly, or to seek better opportunities outside the organization. In response to these challenges, Collaboration Engineering (CE) researchers work to codify facilitation best practices such that practitioners without collaboration expertise could nonetheless learn to run recurring team work processes with repeatable, transferrable success comparable to that of teams led by expert facilitators [24]. The codification of facilitator practices in repeatable facilitation techniques gave rise to a pattern language called 'thinkLets': named, scripted procedures that reliably create predictable variations in the way in which a group moves through its activities towards a shared goal [25]. In other words, a thinkLet specifies how a collaboration professional can guide groups time and again across many situations as it has predictable outcomes in terms of group behaviors. For example, a professional facilitator may apply a specific thinkLet to support a team to make a quick selection from a collection of proposals and apply a different thinkLet when a team needs to be a careful assessment of each proposal. CE researchers categorized thinkLets into six patterns of collaboration, changes-of-state that can be observed over time as they execute their activities: generate, reduce, clarify, organize, evaluate, and build commitment [36].

\subsection{Pattern Languages}

A design pattern is a reusable solution to address a frequently occurring problem. As defined by Alexander " a pattern describes a problem which occurs over and over again and then describes the core of the solution to that problem, in such a way that you can use this solution a million times over, without ever doing it the same way twice" [1] (p. X). A pattern language is a "collection of related design patterns that captures the whole of a design process and can guide the designer through stepby-step design guidelines" [6] (p. 12). In other words, it is a collection of reusable solution elements for recurring design problems [2].

Pattern languages have been proposed for domains from architectural design to software engineering, computer science, instructional design, chess [43] and specifically relevant to this study, Collaboration Engineering (CE) [25]. Of particular interest for this paper is the notion that pattern languages support teaching and transfer of expert knowledge to novices. This has been studied in the context of thinkLets in terms of structuring thinkLets documentation and training programs consisting of lectures, simulation, and coaching such that they facilitate knowledge transfer [24]. The successful transfer of thinkLets as reusable and predictable facilitation techniques was demonstrated in a range of field studies in several countries [24].

\section{Leadership as a Pattern Language}

As mentioned above, CE researchers use the thinkLets pattern language to codify and transfer best facilitation practices $[24,25]$. It can be reasoned that small-group facilitation is a form of leadership and that facilitators are a type of leaders. Therefore, as there are reusable patterns to be found among expert facilitators, so there may be patterns to be found in the interventions of expert leaders, whose fundamental purpose is to influence the behaviors of followers in pursuit of a shared goal $[12,52]$. Hence, we believe that it is beneficial to study leadership behaviors from the lens of pattern languages.

Analyzing leadership from a pattern language perspective offers three potential benefits in the context of AI leadership and leadership development. First, it provides a systematic method for describing interventions. In a recent leadership development metaanalysis [38], the authors express that the varied nature of interventions and lack of sufficient detail make it difficult to review and integrate the leadership interventions into a single framework. This sentiment was reiterated in a personal conversation with the author as well (C. Lacerenza, Sep 11, 2018). A pattern language for leadership interventions can provide a standardized structure for describing all relevant aspects and details of a leadership intervention, making it easier to (a) compare and contrast the attributes of such interventions; (b) replicate studies of specific interventions, and thus develop more precise, reliable, and replicable observations, from which new theories 
can be developed, and (c) provide a pseudo-algorithmic specification of AI leadership functioning [24, 46].

Second, a pattern language facilitates unambiguous communication about leadership interventions. Leadership development experts currently lack a shared language for describing interventions [19]. When a leadership intervention is validated - whether by a practitioner or an academic - dissemination of this knowledge will be more effective if a shared language is used to describe the intervention. A pattern language can serve that purpose. The same applies to developing platform-independent AI leadership foundations; designers need an unambiguous functional specification language that can be shared across development environments and application domains.

Third, a pattern language provides interventions that can be combined and scaled across many contexts and conditions. As noted by Day [20] (see also [22]), there is an important distinction between leader development and leadership development. While leader development focuses on improving the competence of individual leaders, leadership development focuses on the collective (i.e., the leader and his/her followers) and the context in which they operate. Most scholarly interventions have been in the vein of leader development [21]. While these interventions provide important insights, they are limited by their narrow scope - in terms of time and the number of stakeholders targeted. In this setting, a pattern language offers a method to managing the complexity of developing collectives within dynamic contexts. By codifying leadership behaviors into design patterns, leadership actions become like Lego bricks that can be combined and scaled in different ways to meet the demands of a given context. Therefore, the leadership pattern language can begin by capturing basic relationships, but over time and with more data, it is also capable of accommodate more complex interactions [6].

Finally, the use of a pattern language to model and design leadership interventions may also serve as a unifying theoretical glue: As leadership represents a very broad concept, researchers have been trying to study it from various angles to create a complete picture. With a leadership pattern language, we may be able to discover a collection of design patterns that encompasses all parts of the leadership mosaic. In fact, the various theories of leadership, as conflicting as they may be, consistently share one message: there exists a pattern to human behavior, which, if deciphered, will lead to a comprehensive understanding of leadership. We argue that if the series of patterns that outline leadership behaviors are discovered, then these patterns can be initiated and replicated to achieve the leadership goals. In addition,

${ }^{3}$ For the sake of simplicity, we refer to leader and follower as fixed roles. However, we recognize that exerting influence is not always a once the patterns are identified, new leadership strategies can be designed utilizing a series of patterns and current leadership strategies can be also decomposed effectively.

\section{LeadLets: Codified Leadership Practices}

In the previous section, we articulated the value of a pattern-based approach to codifying leadership best practices. In this section, we describe how specific leader actions can produce a predictable outcome in followers. Specifically, we propose that it is possible to systematize leadership best practices into a series of named, scripted leadership techniques. This paper takes a first step towards that end by creating a structure for codifying leadership best practices based on leadership patterns. We call these codified and scripted leadership interventions LeadLets. LeadLets are named, scripted, and repeatable techniques that have a predictable influence causing a purposeful effect on one or more followers.

While effective leadership may be described in many different ways, it can be generally agreed upon that the followers need to favorably respond to the leader for it to be called a leadership process ${ }^{3}$ [44]. That is, to be successful, leaders need to behave in a manner that results in followers achieving the desired goals. To gain a better understanding of this process, it may be useful to break the complex structure of leadership behavior into smaller chunks of actions. In other words, any leadership process can be decomposed into a series of miniature leadership interventions (specific actions by the leader), each of which results in a predicted behavioral response from followers, until the desired goal is reached. For example, a leader who was successful in a completing a team task, may have executed a series of specific behaviors, like clarifying goal of the task, communicating expectations about task performance and time to completion, accepting feedback to improve process or outcome related to task, ensuring cooperation, monitoring progress, and recognizing accomplishments to achieve that goal. Each of these actions can be considered a miniature intervention with an explicit follower response, which as a sequence, led to the leader's desired goal. If such successful interventions (best practices) were to be codified in a manner such that they are repeatable and transferrable across people and applications, they would represent, what we consider, LeadLets.

LeadLets can be used individually or in conjunction with other LeadLets to produce a series of consistent and desired responses from followers, resulting in the accomplishment of the collective's goal(s). In other words, each LeadLet produces an outcome that is

top-down process, and that as a result, a leader will, at times, be following and a follower leading. 
expected from the execution of that specific LeadLet. A single LeadLet's outcome may be different from the final outcome that the leader desires, yet each LeadLet's outcome contributes towards the final outcome. The final leadership outcome can thus be achieved by executing multiple LeadLets that collectively result in the final outcome. Drawing from the example above, the LeadLet to clarify the goals of the task will only accomplish the clarification goal and not the final leadership goal of successful task completion. Yet, its execution is required in sequence with other LeadLets to achieve the desired goal of task completion.

As a pattern language, LeadLets can be used to address recurring situations which have a consistently successful set of solutions or best practices. To highlight the reasoning behind our approach, we outline Alexander's original intentions of a pattern language [2], and describe its potential in the context of leadership, AI leadership, and leadership development:

- Providing a convenient common language for communication: Akin to design patterns, LeadLets are meant to enable leaders and leadership AI designers to name and share complex concepts of leadership interventions without having to explain them repeatedly.

- Inspiring and designing new or improved patterns: A pattern describes a solution to a recurring problem [2]. Based on existing patterns, leadership experts can develop new patterns or combine existing ones to make improvements to the pattern language. LeadLets aim to represent elementary leadership interventions that can be combined to (re)create leadership patterns.

- Designing larger systems based on individual patterns: Patterns provide solutions for problems from a broader perspective [2]. Similarly, LeadLets can be used in combination to create leadership processes and interventions to guide the actions of a group of people towards a specific goal.

- Teaching, capturing and transferring expert design knowledge to novices: Alexander [2] originally intended to use design patterns to support capturing and sharing expert knowledge. LeadLets aim for the same: To capture best leadership practices from literature and experienced leaders so that these can be transferred to novices and AI agents for them to execute these practices and achieve similar results.

- Enabling 'anyone' to create with patterns: Similar to Alexander's [2]purpose that anyone should be able to use his design patterns to design homes and other buildings, LeadLets are meant to enable anyone - human or AI agent - to field a successful leadership intervention.

- Creating coherent systems: A pattern language is a hierarchical system to create complete and coherent systems rather than a loose collection of individual components $[1,2]$. Similarly, LeadLets represent a collection of complementary building blocks to create leadership processes that can be executed by humans or AI artifacts.

\section{Method}

Our research aims to develop a pattern-based approach to modeling and designing leadership interventions to inform AI leadership design and leadership development programs. Key components of our research include (a) to demonstrate that there are specific best leadership practices that can be gathered and codified as LeadLets from the experience of seasoned leaders, and (b) that there are patterns of leaderships that represent collections of LeadLets that serve a similar purpose.

\subsection{Data Collection}

One of the goals of the study was to identify specific leader behaviors that are reusable, have a predictable outcome, and are easily transferable to new contexts and convert them into LeadLets. As described earlier, prior research does not readily provide clear descriptions of behaviors that meet all of these criteria, so it was necessary to collect original data. Accordingly, thirteen leaders (five women and eight men) were interviewed using a semi-structured interview protocol. The interview questions were developed based on the initial conceptualization of a LeadLet and previous experiences from the authors codifying thinkLets.

Participants were recruited through the authors' professional networks. Potential participants were approached based on their demonstrable leadership experience and expected willingness to reflect on their leadership experience. To maximize variation in responses, participants were recruited from multiple industries (e.g., construction, public health, information technology, financial services, and higher education) and career stages (management experience ranged from 5 to 30 years). Participants were asked to describe behaviors they employ because they have observed that they consistently produce the desired response in their followers. The interviewers asked additional questions to extract relevant information, e.g. "What technique did you use," "What is the desired effect of the technique," "Under what conditions would you use or not use this technique?" The interviews were conducted either in person or over the phone. They were audio-recorded and lasted between 30 to 80 minutes.

\subsection{Data Analysis}

Coding structure. It is critical to know which conditions need to be met and what actions need to be taken to recreate a leadership behavior pattern. It must also be stated when the LeadLet will be and will not be 


\begin{tabular}{|c|c|c|}
\hline \multicolumn{3}{|c|}{ Description of the LeadLet - This five-part component provides a holistic understanding of the LeadLet. } \\
\hline Name: & \multicolumn{2}{|r|}{ Name of the LeadLet } \\
\hline Purpose: & \multicolumn{2}{|c|}{ The that the LeadLet is expected to achieve } \\
\hline Pattern: & \multicolumn{2}{|c|}{ The general category of leadershin influence this LeadLet should invoke } \\
\hline Effect: & \multicolumn{2}{|r|}{ The specific response expected from the followers if the LeadLet is successfully executed } \\
\hline Time Frame: & \multicolumn{2}{|r|}{ The estimated amount of time it will take to execute the LeadLet and gain its intended effect } \\
\hline Overview: & \multicolumn{2}{|r|}{ A summary of the actions the leader should take to instantiate the LeadLet. } \\
\hline \multicolumn{3}{|c|}{ Implementation of the LeadLet - This two-part component elaborates on how the LeadLet is to be instantiated. } \\
\hline \multicolumn{3}{|c|}{ What you need to have: Capabilities (such as tools and materials) required to instantiate the LeadLet. } \\
\hline \multicolumn{3}{|c|}{ What you need to do: Sequence of actions and instructions to invoke the desired effect among the followers } \\
\hline \multicolumn{3}{|c|}{ Usage Guidelines - This three-part component informs the leader of when the LeadLet is most and least effective. } \\
\hline \multicolumn{2}{|c|}{ Necessary Conditions: } & Conditions that need to be met for the LeadLet to be effective. \\
\hline \multicolumn{2}{|c|}{ When to Choose: } & Situations that lend themselves to the most effective instantiation of the LeadLet. \\
\hline \multicolumn{2}{|c|}{ When Not to Choose: } & Situations that are least conducive to the effective instantiation of the LeadLet. \\
\hline
\end{tabular}

Table 1. LeadLet conceptual structure.

\begin{tabular}{|c|c|}
\hline \multicolumn{2}{|c|}{ ENHANCING UNDERSTANDING } \\
\hline Illuminate & Present irrefutable evidence to spur followers to infer beliefs regarding the situation at hand \\
\hline EthicalCompass & Clarifying the team's clear belief systems to enable evaluation of issues at hand \\
\hline ProblemScout & Creating a shared vision of the nature of the problem \\
\hline OnePager & Requiring a precise understanding of the issue before bringing it to a group for discussion \\
\hline EmbraceReality & Enabling followers to evaluate their self perceptions with their peers' in a fully transparent environment \\
\hline LucidGoal & Deliberating on the goals to enable a clear understanding of why the problem should be addressed \\
\hline \multicolumn{2}{|c|}{ STRENGTHENING MOTIVATION } \\
\hline TrustCluster & Creating a group of followers who are loyal and honest to weigh the desirability of alternate options \\
\hline CheerLeader & $\begin{array}{l}\text { Identifying respected members of the organization who can support the goal to facilitate a broader buy-in } \\
\text { among all followers }\end{array}$ \\
\hline GroupConsulter & Inviting followers to weigh in on alternative options to hear all relevant considerations \\
\hline \multicolumn{2}{|c|}{ FACILITATING IMPLEMENTATION } \\
\hline ConcentricCircles & Establishing buy-in and feedback of a group regarding a decision \\
\hline ProgressMonitor & Identifying obstacles and keeping followers on track \\
\hline \multicolumn{2}{|c|}{ FOSTERING COORDINATION } \\
\hline PTA (PersonToAct) & Assigning specific action items to specific followers \\
\hline SmartAssign & Assigning appropriate roles and responsibilities to followers \\
\hline SmartConnect & Being a conduit of information between followers \\
\hline \multicolumn{2}{|c|}{ PROMOTING COOPERATION } \\
\hline CommandersIntent & Encouraging followers to use their own judgment on the best way to reach the leader's goal \\
\hline TourOfDuty & Encouraging followers to utilize their strengths in the pursuit of the leader's goal \\
\hline \multicolumn{2}{|c|}{ ACTIVATING RESOURCES } \\
\hline IdeaClay & Ensuring that ideas remain pliable and don't get rigidly owned by followers \\
\hline CritiqueClearnace & Actively encouraging followers to provide constructive feedback \\
\hline CoffeeWithTheBoss & Encouraging and offering social support to reduce barriers and energize followers to support the leade \\
\hline
\end{tabular}

Table 2. Overview of LeadLets identified during the interviews.

effective. Without such information, leaders may not be able to reproduce results. LeadLets also need to be parsimonious to be easily transferrable. Considering these criteria and drawing inspiration from the structure adapted from the thinkLets research, a LeadLet was determined to consist of three major components: Description, Implementation, and Usage Guidelines (Table 1).

Coding process. The first three authors independently listened to the interviews, first noting each instance of a specific leader action that the interviewee claimed produced a consistent outcome in his or her followers. Then, these authors met to create a list of unique leader actions and the respective follower outcomes for each leader. This resulted in 30 candidate LeadLets. Next, these initial LeadLets were organized into one of six leadership patterns, see Results section for details [11]. This was done by having two coders independently assign each LeadLet to a pattern. When there was disagreement it was resolved through discussion until there was consensus regarding all aspects of the LeadLet. During this process, four LeadLets were dropped from the set as they were not specific enough or represented a more generic leadership strategy rather than an intervention. Also, seven LeadLets overlapped and were consolidated. This left 19 unique LeadLets (Table 2). 


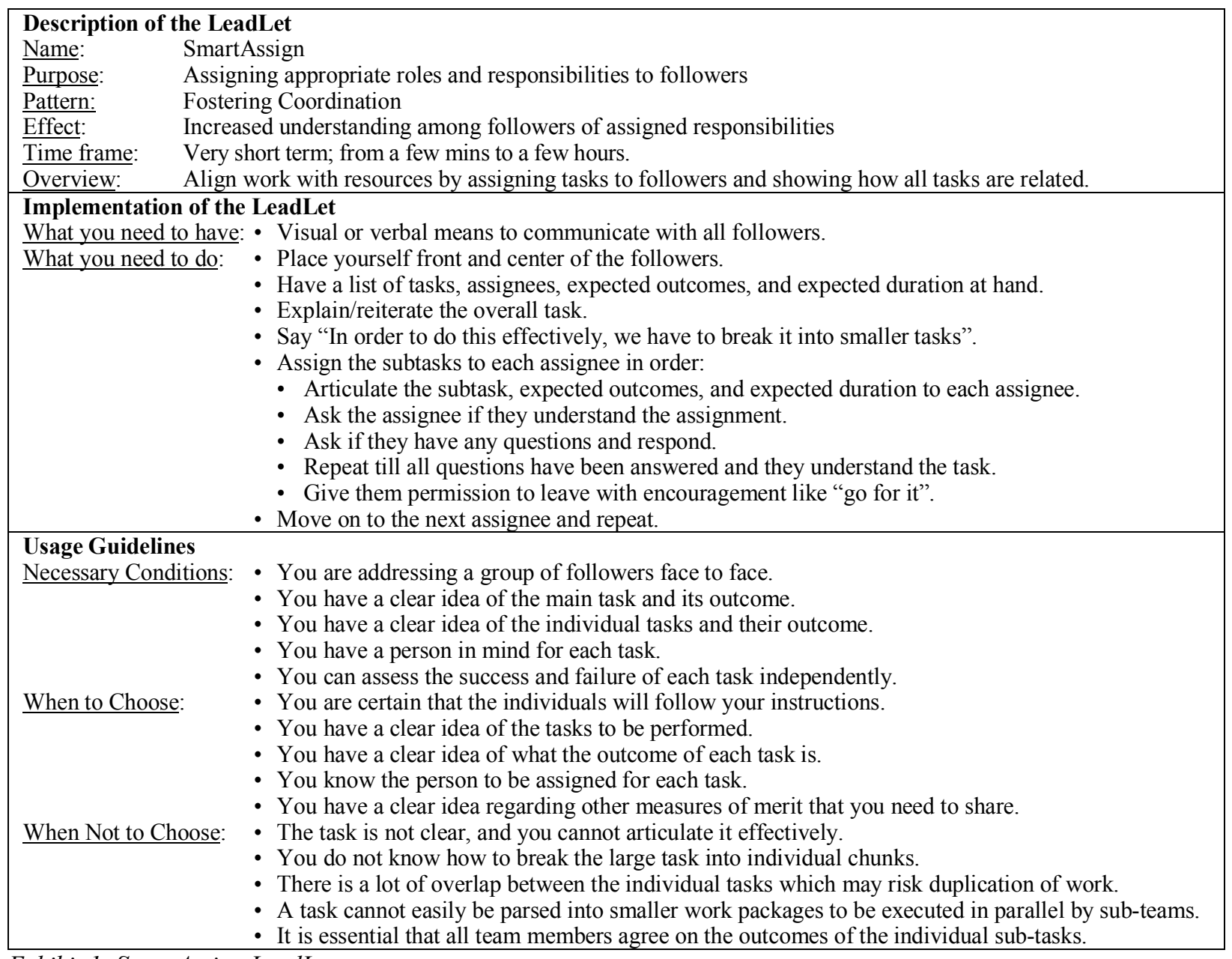

Exhibit 1: SmartAssign LeadLet.

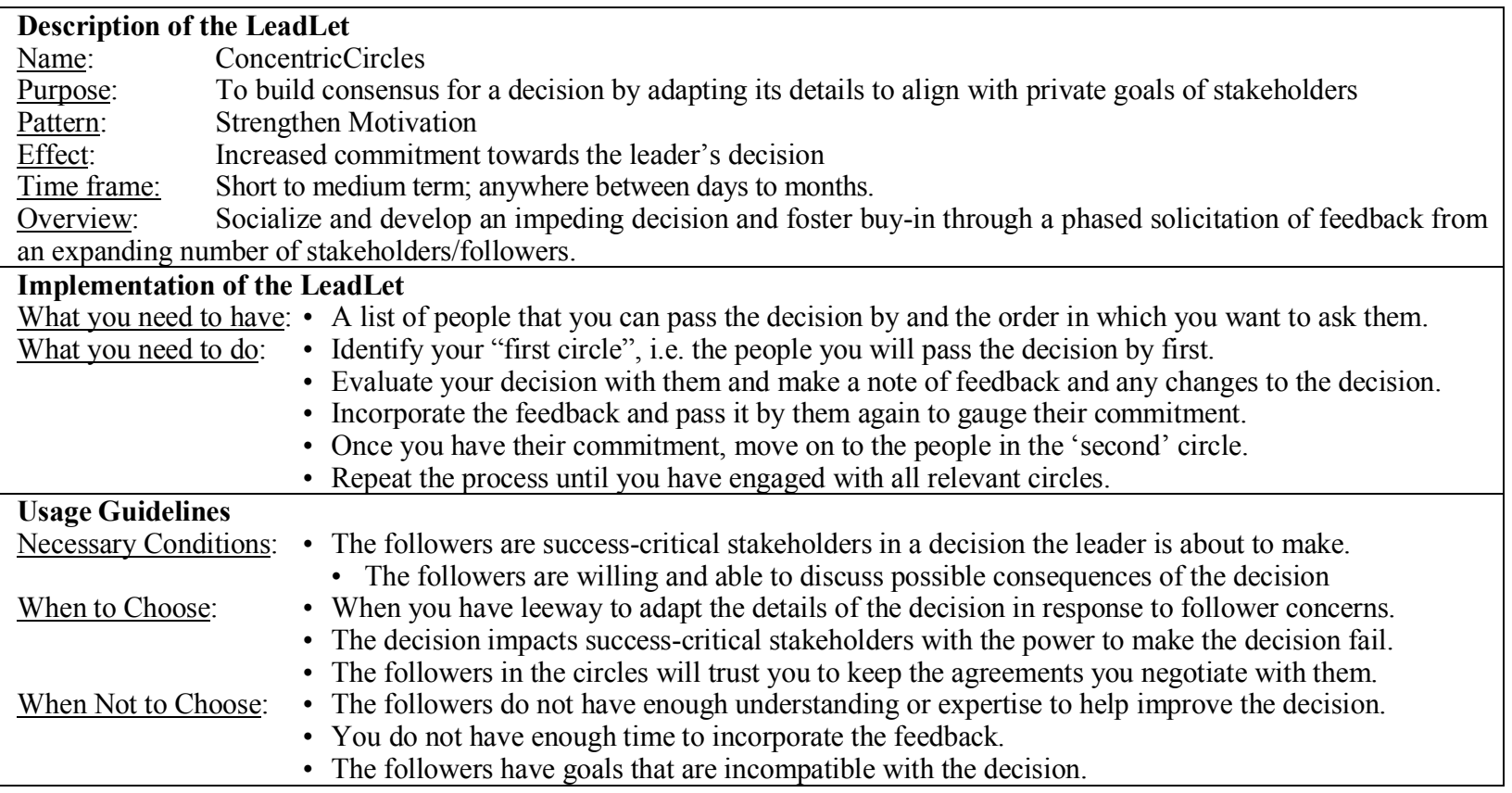

Exhibit 2: ConcentricCircles LeadLet. 


\begin{tabular}{|c|c|}
\hline $\begin{array}{l}\text { Enhancing Understanding - Anything that the leader says or } \\
\text { does to improve the understanding of the followers to inform } \\
\text { their purposeful action towards the leader's goal. Includes, but } \\
\text { is not limited to: } \\
\text { a. Evaluating prior actions and their results } \\
\text { b. Attributing the results to causes and people } \\
\text { c. Providing information } \\
\text { d. Inferring beliefs regarding the situation at hand, the } \\
\text { situation's supporting and hindering factors and actors, } \\
\text { e. Encouraging self-reflection } \\
\text { f. Creating a shared vision of the goal } \\
\text { g. Creating accountability }\end{array}$ & $\begin{array}{l}\text { Strengthening Motivation - Anything that the leader says or } \\
\text { does to increase the willingness of the followers to work } \\
\text { towards the leader's goal. Includes, but is not limited to: } \\
\text { a. Deliberating possible objectives and their } \\
\text { consequences } \\
\text { b. Weighing the desirability of the alternative objectives } \\
\text { c. Deriving concrete intentions } \\
\text { d. Strengthening the motivation to pursue shared goals } \\
\text { and individual goals that support the shared goals by } \\
\text { focusing on the value of positive consequences, } \\
\text { approval by relevant others and the motivation to } \\
\text { comply with these relevant others } \\
\text { e. Achieving buy-in }\end{array}$ \\
\hline $\begin{array}{l}\text { Facilitating Implementation - Anything that the leader says } \\
\text { or does to determine how best the followers can go about } \\
\text { attaining the leader's goal. Includes, but is not limited to: } \\
\text { a. Forming implementation plans and plans for } \\
\text { b. Acquiring resources and gaining support } \\
\text { c. Developing skills } \\
\text { d. Identifying opportunities for implementation } \\
\text { e. Activating, focusing and guiding implementation }\end{array}$ & $\begin{array}{l}\text { Fostering Coordination - Anything that the leader says or } \\
\text { does to appropriately align available resources to facilitate } \\
\text { attainment of the leader's goal. Includes, but is not limited to: } \\
\text { a. Communicating the procedure explicitly and } \\
\text { b. Ensintaining the structure of communication } \\
\text { c. Employing standardized processes } \\
\text { d. Conveying personal competence and certainty while } \\
\text { doing the above }\end{array}$ \\
\hline $\begin{array}{l}\text { Promoting Cooperation - Anything that the leader says or } \\
\text { does to facilitate maximum shared effort of the followers } \\
\text { towards the leader's goal. Includes, but is not limited to: } \\
\text { a. Encouraging individual contributions to the group's } \\
\text { progress } \\
\text { b. Underlining these individual contributions and their } \\
\text { uniqueness and indispensability to and effect on } \\
\text { collective progress } \\
\text { c. Encouraging and offering social support } \\
\text { d. Delegating individual tasks based on comprehensive } \\
\text { work-role-fit regarding interests, competence, and } \\
\text { e. Permitting autonomy in tasks to allow for self- } \\
\text { f. Encouraging to resolve issues through communication }\end{array}$ & $\begin{array}{l}\text { Activating Resources - Anything that the leader says or does } \\
\text { to enable the followers to pursue the leader's goal. Includes, } \\
\text { but is not limited to: } \\
\text { a. Suggesting or instructing self-efficacy } \\
\text { b. Highlighting positive experiences, past successes, and } \\
\text { feasible future accomplishments } \\
\text { c. Focusing positive attributes of individuals and the } \\
\text { group as a whole } \\
\text { d. Fostering the expectation to collectively divert } \\
\text { impending power losses or to achieve power gains } \\
\text { e. Rewarding and recognizing to call forth and shape } \\
\text { f. Redure valuable contributions } \\
\text { g. Permitting constructive criticism }\end{array}$ \\
\hline
\end{tabular}

Table 3. Taxonomy of leadership patterns. Adapted from [11].

\section{Results}

As stated, this study codified 19 unique LeadLets. In addition to identifying LeadLets, a series of patterns of leadership were also identified that appeared to recur for a number of related LeadLets. Based on evaluation of the LeadLets and a review of the literature, these patterns were arranged into a taxonomy of six leadership patterns [45]. These should not be confused with design patterns that codify leadership techniques. Consistent with the leadership definition provided earlier, two fundamental leader responsibilities in pursuit of a goal can be derived: (1) the process for accomplishing the goal (i.e. the first three leadership-patterns), and (2) the level of effort their followers invest toward goal attainment (i.e. the other three leadership-patterns) (see Table 3).
A high-level overview of the 19 identified LeadLets is provided in Table 2, including the distribution of the LeadLets among the leadership-patterns. As space constraints preclude the presentation of each LeadLet's details, we illustrate the nature of a leadership design patterns and the information that is captured for a LeadLet for two examples (see Exhibits 1 and 2).

With respect to the codified LeadLets, it is important to note that leadership situations are highly unstructured and can take on several forms. Therefore, when identifying behavior patterns of leaders, one must consider relevant boundary conditions, such as the duration of the leader/follower relationship, the timeframe of the leadership intervention, the size of the follower group, the degree to which goals are already clear, and the degree to which a leadership problem is structured vs. wicked, to name but a few. In this first study, we focused on leadership scenarios with a clear goal for the collective and explored LeadLets for situations with a small number of followers. Additional 
research is required both for these conditions and the many other conditions under which leaders operate to discover the and codify the root concepts underpinning leadership and followership. In addition, there may be different ways in which individual leaders instantiate the the required behaviors to execute a LeadLet in a specific situation. Additional work is required to determine whether a deeper level of prescriptive detail is required for novice leaders to faithfully and effectively execute the LeadLets using the current 'what you need to do' guidance.

We submit though, that the work in this paper sets a stage for future empirical evaluations of the generalizability and effectiveness of specific LeadLets across a range of conditions. As the collection of LeadLets grows and develops, the scenarios in which they are useful (e.g., senior leaders navigating crises, long-duration teams, etc.) is likely to expand.

\section{Discussion \& Conclusions}

This paper proposes a new perspective on leadership interventions, a pattern language, called LeadLets. There are a number of implications to a pattern language perspective. First, the conceptualization of leadership behavior as a sequence of distinct LeadLets can serve as the foundation to the development of leadership algorithms and structures. This conceptualization represents a first step to facilitate the implementation of AIs with decision-tree and machine learning approaches to evaluating leadership situations and instantiating LeadLets from a repository. Such instantiations may also take place in settings that use Virtual or Augmented Reality that mimic face-to-face interactions between leaders and followers.

Second, LeadLets may be useful to enhance the effectiveness of leadership development programs. A specific collection of LeadLets can be identified and included in a training program where aspirant leaders receive guidance on how to select and apply each LeadLet. Distinct collections of LeadLets could be developed for specific application domains like strategic leadership, operational leadership, and negotiation. Specifying coherent collections of LeadLets would enable the design of targeted leadership development programs.

Third, the leadership literature reports inconsistent findings on leadership interventions. A meta-analysis on discovered significant variability in the effectiveness of each approach, even after accounting for the effects of hypothesized moderators [7]. It could be worthwhile to reexamine these findings by codifying the interventions as LeadLets studies to discover whether the variations could be attributed to subtle, but important differences in one or more of the LeadLet elements. LeadLets may provide a useful format to report interventions in leadership experiments, making it easier to replicate studies.

Finally, LeadLets provide a useful format to report interventions in leadership experiments such that it becomes easier to replicate studies. Without sharing the exact information that is required to accurately codify a leadership intervention, other researchers cannot be sure what specific actions they have to perform under certain circumstances to stimulate the desired behavior among the followers. Thus, adopting the LeadLet format for research reporting could enhance replicability in leadership development research.

While this paper lays out the background of a pattern language for leadership, there are several limitations that require additional work to expand on this new perspective on leadership research and practice. New interviews with experienced leaders are under way to expand the collection of LeadLets and refine existing ones. A next step would be to validate the collection of LeadLets with a panel of leaders, different from the interviewees. Future work may improve the format and contents of LeadLet documentation. This includes not only the actions that leaders take, but also the situations in which those actions are taken (e.g., organizational culture, crises, time pressure), the characteristics of the followers who are acted upon (e.g., tenure, skill level), and the quality of the relationship between leaders and their followers. As noted earlier, leadership development involves all of these elements, and it would undermine the effectiveness of an intervention to focus solely on the actions of the leader. This is especially true as it applies to the leader-follower relationship, which recent metaanalytic work has observed plays a central role in the effect leaders can have on their followers [33, 42].

Further work may also determine whether leadership patterns and LeadLets vary across industries. Since our interviews involved leaders from multiple industries, it is possible that the codified LeadLets may have limited applicability to a specific industry.

Furthermore, as work progresses, researchers may be able to derive a smaller set of fundamental principles upon which all LeadLets are founded, which may make it possible to reduce the larger body of discovered LeadLets to a smaller canonical set that can be adapted across a broader range of contexts. Better LeadLet codification and classification may, in turn, make it easier to conceive new LeadLets to address previously intractable leadership problems. It may also provide a simpler foundation for developing algorithms to implement leadership behaviors in AI entities, the ultimate goal of the research stream this paper launches. Finally, it may be possible to incorporate a set of validated LeadLets into a blueprint leadership development program, and to make comparative assessments of 
the quality of the such programs through observational and experimental assessments of trainee performance.

As researchers explore the LeadLets concept in a variety of domains across a variety of leadership scenarios, such as strategic leadership or crisis leadership, researchers may establish theoretical models to explain and predict the repeatable effects produced by LeadLets. Why does a LeadLet work and under what circumstances? Developing the theoretical foundations for each LeadLets would support the development of additional LeadLets and guide experimental research to demonstrate the value of particular interventions. Finally, LeadLets can also be explored in other problem spaces where leadership is not as restricted in terms of time, space, and membership. For instance, to improve the perception of the CEOs towards their employees or political leaders towards their constituents.

The concept of leadership is analogous to the metaphorical elephant that researchers have been trying to comprehensively understand from various angles. By integrating (sometimes contradictory) theories into a coherent mosaic, leadership researchers have pushed the boundaries of our understanding of what leadership is. Building on this vast body of leadership research, we propose enriching it with a bottom-up, pattern-based perspective that may help capture effective leadership interventions to inform leadership development of human and AI agents. A leadership pattern language may encompass all relevant parts of the mosaic of this metaphorical elephant and may even highlight any missing parts. If a rich collection of patterns that outline various leadership behaviors are discovered, then these behaviors can be consistently repeated and passed on to future (AI-based) leaders, thereby bringing the concept of leadership development to a new level.

\section{References}

[1] C. Alexander, A pattern language: towns, buildings, construction. Oxford university press, 1977.

[2] C. Alexander, The timeless way of building. New York: Oxford University Press, 1979.

[3] J. Antonakis, "On doing better science: From thrill of discovery to policy implications," The Leadership Quarterly, vol. 28, no. 1. 2017, pp. 5-21.

[4] J. Antonakis and D. V. Day, The nature of leadership. Sage publications, 2017.

[5] J. Antonakis, B. J. Avolio, and N. Sivasubramaniam, "Context and leadership: An examination of the nine-factor full-range leadership theory using the Multifactor Leadership Questionnaire," The leadership quarterly, vol. 14, no. 3. 2003, pp. 261-295.

[6] P. Avgeriou and U. Zdun, "Architectural patterns revisited-a pattern language." 2005,

[7] B. J. Avolio, R. J. Reichard, S. T. Hannah, F. O. Walumbwa, and A. Chan, "A meta-analytic review of leadership impact research: Experimental and quasi- experimental studies," The leadership quarterly, vol. 20, no. 5. 2009, pp. 764-784.

[8] J. Bally, "The Thunderstorm Interactive Forecast System: Turning automated thunderstorm tracks into severe weather warnings," Weather and forecasting, vol. 19, no. 1. 2004, pp. 64-72.

[9] B. Bass and B. Avolio, MLQ multifactor leadership questionnaire. Mind Garden, 1995.

[10] B. M. Bass, "Does the transactional-transformational leadership paradigm transcend organizational and national boundaries?," American psychologist, vol. 52, no. 2. 1997, p. 130.

[11] P. Behrendt, S. Matz, and A. S. Göritz, "An integrative model of leadership behavior," The leadership quarterly, vol. 28, no. 1. 2017, pp. 229-244.

[12] W. Bennis, "The challenges of leadership in the modern world: Introduction to the special issue," American psychologist, vol. 62, no. 1. 2007, p. 2.

[13] R. Blake and J. Mouton, "The managerial grid: The key to leadership excellence," Houston: Gulf Publishing Co. 1964, p. 350.

[14] R. O. Briggs, G.-J. De Vreede, and J. F. Nunamaker Jr, "Collaboration engineering with ThinkLets to pursue sustained success with group support systems," Journal of management information systems, vol. 19, no. 4. 2003, pp. 3164.

[15] M. E. Brown, L. K. Treviño, and D. A. Harrison, "Ethical leadership: A social learning perspective for construct development and testing," Organizational behavior and human decision processes, vol. 97, no. 2. 2005, pp. 117-134. [16] C. S. Burke, K. C. Stagl, C. Klein, G. F. Goodwin, E. Salas, and S. M. Halpin, "What type of leadership behaviors are functional in teams? A meta-analysis," The leadership quarterly, vol. 17, no. 3. 2006, pp. 288-307.

[17] A. M. Carton, C. Murphy, and J. R. Clark, "A (blurry) vision of the future: How leader rhetoric about ultimate goals influences performance," Academy of Management Journal, vol. 57, no. 6. 2014, pp. 1544-1570.

[18] J. A. Conger and R. N. Kanungo, "Toward a behavioral theory of charismatic leadership in organizational settings," Academy of management review, vol. 12, no. 4. 1987, pp. 637647.

[19] D. V. Day and Z. Liu, "What Is Wrong with Leadership Development and What Might Be Done about It?," What's Wrong With Leadership?: Improving Leadership Research and Practice. 2018,

[20] D. V. Day, "Leadership development:: A review in context," The leadership quarterly, vol. 11, no. 4. 2000, pp. 581-613.

[21] D. V. Day and A. M. A. Thornton, "Leadership development," in The nature of leadership J. Antonakis and D. V. Day Eds., 3 ed. Thousand Oaks, CA: Sage Publications., 2018, pp. 354-380.

[22] D. V. Day, J. W. Fleenor, L. E. Atwater, R. E. Sturm, and R. A. McKee, "Advances in leader and leadership development: A review of 25 years of research and theory," The leadership quarterly, vol. 25, no. 1. 2014, pp. 63-82.

[23] D. V. Day and J. Antonakis, "The future of leadership," The Wiley-Blackwell handbook of the psychology of leadership, change, and organizational development. 2013, pp. 221-235. 
[24] G.-J. de Vreede and R. O. Briggs, "A Program of Collaboration Engineering Research \& Practice: Contributions, Insights, and Future Directions," Journal of Management Information Systems., vol. 36, no. 1. 2019, pp. 74-119.

[25] G.-J. De Vreede, G. L. Kolfschoten, and R. O. Briggs, "ThinkLets: a collaboration engineering pattern language," International Journal of Computer Applications in Technology, vol. 25, no. 2-3. 2006, pp. 140-154.

[26] D. Derrick and J. Elson, "Exploring Automated Leadership and Agent Interaction Modalities," in Proceedings of the 52nd Hawaii International Conference on System Sciences, 2019.

[27] D. C. Derrick and J. S. Elson, "Automated leadership: Influence from embodied agents," in International Conference on HCI in Business, Government, and Organizations, 2018: Springer, pp. 51-66.

[28] J. E. Dinh, R. G. Lord, W. L. Gardner, J. D. Meuser, R. C. Liden, and J. Hu, "Leadership theory and research in the new millennium: Current theoretical trends and changing perspectives," The Leadership Quarterly, vol. 25, no. 1. 2014, pp. 36-62.

[29] P. Drucker, "The manager and the moron," McKinsey Quarterly, vol. 3, no. 4. 1967, p. 42.

[30] E. A. Fleishman, M. D. Mumford, S. J. Zaccaro, K. Y. Levin, A. L. Korotkin, and M. B. Hein, "Taxonomic efforts in the description of leader behavior: A synthesis and functional interpretation," The Leadership Quarterly, vol. 2, no. 4. 1991, pp. 245-287.

[31] F. Galton, Hereditary genius: An inquiry into its laws and consequences. Macmillan, 1869.

[32] M. Georgeff and F. Ingrand, "Decision-making in an embedded reasoning system," in International Joint Conference on Artificial Intelligence, 1989.

[33] R. K. Gottfredson and H. Aguinis, "Leadership behaviors and follower performance: Deductive and inductive examination of theoretical rationales and underlying mechanisms," Journal of Organizational Behavior, vol. 38, no. 4. 2017, pp. 558-591.

[34] J. Hemphill and A. Coons, "Leader behavior: Its description and measurement," Columbus, OH: Bureau of Business Research, Ohio State University.[Google Scholar]. 1957 ,

[35] T. A. Judge, R. F. Piccolo, and R. Ilies, "The forgotten ones? The validity of consideration and initiating structure in leadership research," Journal of applied psychology, vol. 89, no. 1. 2004, p. 36.

[36] G. L. Kolfschoten, G.-J. de Vreede, and L. R. Pietron, "A training approach for the transition of repeatable collaboration processes to practitioners," Group Decision and Negotiation, vol. 20, no. 3. 2011, pp. 347-371.

[37] J. M. Kouzes and B. Z. Posner, The leadership challenge. John Wiley \& Sons, 2006.

[38] C. N. Lacerenza, D. L. Reyes, S. L. Marlow, D. L. Joseph, and E. Salas, "Leadership training design, delivery, and implementation: A meta-analysis," Journal of Applied Psychology, vol. 102, no. 12. 2017, p. 1686.

[39] R. C. Liden, S. J. Wayne, H. Zhao, and D. Henderson, "Servant leadership: Development of a multidimensional measure and multi-level assessment," The leadership quarterly, vol. 19, no. 2. 2008, pp. 161-177.

[40] R. G. Lord, D. V. Day, S. J. Zaccaro, B. J. Avolio, and A. H. Eagly, "Leadership in applied psychology: Three waves of theory and research," Journal of Applied Psychology, vol. 102 , no. 3. 2017, p. 434.

[41] F. Luthans and B. J. Avolio, "Authentic leadership development," Positive organizational scholarship, vol. 241. 2003, p. 258.

[42] T. W. Ng, "Transformational leadership and performance outcomes: Analyses of multiple mediation pathways," The Leadership Quarterly, vol. 28, no. 3. 2017, pp. 385-417.

[43] H. M. Niegemann and S. Domagk, "ELEN project evaluation report," University of Erfurt, Erfurt. 2005,

[44] C. L. Pearce and H. P. Sims Jr, "Vertical versus shared leadership as predictors of the effectiveness of change management teams: An examination of aversive, directive, transactional, transformational, and empowering leader behaviors," Group dynamics: Theory, research, and practice, vol. 6, no. 2. 2002, p. 172.

[45] M. E. Pollack, "Intelligent technology for an aging population: The use of AI to assist elders with cognitive impairment," AI magazine, vol. 26, no. 2. 2005, pp. 9-9.

[46] E. L. Santanen and G.-J. de Vreede, "Creative approaches to measuring creativity: comparing the effectiveness of four divergence thinklets," in 37th Annual Hawaii International Conference on System Sciences, 2004. Proceedings of the, 2004: IEEE, p. 10 pp.

[47] I. Seeber et al., "Machines as teammates: a collaboration research agenda." 2018,

[48] N. Sharma and V. Banga, "Drowsiness warning system using artificial intelligence," World Academy of Science, Engineering and Technology, vol. 4, no. 7. 2010, pp. 17711773.

[49] R. M. Stogdill, Manual for the leader behavior description questionnaire-Form XII: An experimental revision. Bureau of Business Research, College of Commerce and Administration, Ohio ..., 1963.

[50] D. Van Knippenberg and S. B. Sitkin, "A critical assessment of charismatic - transformational leadership research: Back to the drawing board?," The Academy of Management Annals, vol. 7, no. 1. 2013, pp. 1-60.

[51] P. A. Vermeulen, "Uncovering barriers to complex incremental product innovation in small and medium-sized financial services firms," Journal of Small Business Management, vol. 43, no. 4. 2005, pp. 432-452.

[52] G. Yukl, "Effective leadership behavior: What we know and what questions need more attention," Academy of Management Perspectives, vol. 26, no. 4. 2012, pp. 66-85. 